\title{
EFFECTS OF HOME EXERCISE PROGRAMME ON SHOULDER PAIN AND FUNCTIONAL STATUS IN MALE CONSTRUCTION WORKERS
}

\author{
MALARVIZHI D*, DIVYA D, SIVAKUMAR VPR \\ Department of Physiotherapy, SRM College of Physiotherapy, SRM University, Chennai, Tamil Nadu, India. \\ Email: malarvizhi.d@ktr.srmuniv.ac.in
}

Received: 13 January 2017, Revised and Accepted: 14 March 2017

\section{ABSTRACT}

Objective: To evaluate the effect of home exercise program on shoulder pain and functional status in male construction workers.

Methods: Study design was quasi-experimental study, subjects were 30 male construction workers, n=15 Group A (experimental) and n=15 Group B (control). Subjects in the experimental group were instructed in a 6 weeks home exercise program, Group B subjects were treated with only ergonomic advices. The outcome measurements were visual analog scale and shoulder pain and disability index.

Results: The results of this study showed that significant reduction in pain and improvement in the functional status of construction workers in Group A than Group B.

Conclusion: The study concluded that there was a significant reduction in shoulder pain and improvement in functional status by home exercise program than ergonomic advices in male construction workers.

Keywords: Construction workers, Shoulder pain, Home exercises, Visual analog scale, Shoulder pain and disability index.

(C) 2017 The Authors. Published by Innovare Academic Sciences Pvt Ltd. This is an open access article under the CC BY license (http://creativecommons. org/licenses/by/4. 0/) DOI: http://dx.doi.org/10.22159/ajpcr.2017.v10i6.17080

\section{INTRODUCTION}

Repetitive or sustained elevated postures should have been identified as a significant risk factor for occupationally related musculoskeletal disorders of the shoulder. The evidence of occupational risk is strongest for combined exposure to multiple physical factors, such as holding tools while working overhead. Prevalence of shoulder pain is $64 \%$ in men, $36 \%$ in women [1].

Construction workers in many trades, by the nature of their work, have substantial exposure to awkward postures, repetitive and forceful muscular contractions, and overhead work. Construction workers exposed to routine overhead work have high rates of shoulder pain that frequently progresses to functional loss and disability [2].

Shoulder pain which occurs in construction workers is due to overhead working which leads to impingement syndrome which is one of the major causes.

Shoulder impingement, defined as compression and irritation of the rotator cuff structures as they pass beneath the coracoacromial arch during elevation of the arm [3,4].

When the arm is raised, the subacromial space (gap between the anterior edge of the acromion and the head of the humerus) narrows, through which the supraspinatus muscle tendon passes. Anything that causes further narrowing has the tendency to impinge the tendon and cause an inflammatory response, resulting in impingement syndrome [3,4].

This may occur during repetitive arm elevation activities, overhead activities, reaching activities far away from the body, activities involving rotation of the shoulder, lifting (especially overhead), pushing or pulling activities, placing weight through the affected arm or lying on the affected side.

Construction is a physically demanding occupation, but a vital part of our nation and the Indian economy. This large workforce handled tasks that range from carrying heavy loads to performing repetitive tasks, placing them at risk of serious injury. The physically demanding nature of this work helps to explain why injuries, such as strains, sprains, and work-related musculoskeletal disorders (WMSDs), are so prevalent and are the most common injury resulting in days away from work [5].

WMSDs are caused by job activities and conditions such as lifting, repetitive motions, and work in confined areas. All of these are part of construction work [5].

On some construction jobs they need to work overhead, reaching up with one or both arms raised above the shoulders. Their head may be tilted back, looking up to see what they are doing. Whether they are drilling, finishing dry wall, overhead work puts stress on their shoulders. Eventually, it may lead to serious muscle and joint injuries [2].

Shoulder pain or a shoulder muscle or joint disorder is increased by the combination of frequently working with raised shoulders $\left(60^{\circ}\right.$ or more). Overhead work cannot be eliminated from construction, but it is possible to change how they do it so it is easier on their body. Solutions are available that can reduce the level of stress on their shoulders, and arms. Working with a lightweight block can improve their output during the day and still decrease the total weight they lift. Less weight means they will be less tired and there will be less stress on the shoulder, hands, and arms [5].

The aim of the study was to evaluate the effect of home exercise program on shoulder pain and functional status in male construction workers. In foreign countries, many construction contractors were utilizing standard group stretching and strengthening exercises programs with before daily work. These programs generally attempt to provide a "warm up" for workers for a number of joints. We can implement such stretching and strengthening exercise program among construction workers in our country to prevent the occupational musculoskeletal injuries. 


\section{METHODS}

A total of 30 construction workers were selected according to inclusion and exclusion criteria. It was a quasi-experimental study and pre- and post-test type. It was a 6 weeks study conducted in Perumbakkam, Chennai, construction site. Inclusion criteria were visual analog scale (VAS) with the moderate range of 3-6, shoulder impingement syndrome, and shoulder pain localized to the glenohumeral joint. Exclusion criteria for this study were a history of rotator cuff surgery, history of glenohumeral dislocation, other traumatic injuries of the shoulder, and cervical spondylosis with nerve impingement.

About 30 male subjects were selected for the study based on the inclusion and exclusion criteria at the initial visit and subjects were informed, and consent was taken. Institutional Ethical Committee approval also obtained before starting the study.

All the male subjects undergone a standard clinical examination, VAS and to complete the shoulder pain and disability index (SPADI) and to answer work-related questions, before starting of the study (pre-test) and after 6 weeks (post-test).

- Group A: 15 male subjects

- Group B: 15 male subjects.

About 15 male (Group A) subjects undergone a treatment protocol for 6 weeks which consist of three therapeutic interventions [6].

- Free exercises for the first 2 weeks

- Strengthening exercises for the next 2 weeks

- Stretches for the past 2 weeks.

\section{Free exercises includes}

Codman's pendular exercises, wall climbing with fingers was performed by subject standing sideways, subjects were in stride standing and arm was swinging across, sideways and circling and strengthening exercises were performed for all the shoulder muscles with dumbbells (10 repetition maximum).

\section{Strengthening}

\section{External rotators}

The subject lies on their side with the arm to be worked on top. The upper arm should be resting on therapist side, and the elbow bent so that the hand points toward the floor. Rotate the shoulder so that the hand moves up, toward the ceiling as far as possible. Slowly return to the starting position.

\section{Internal rotators}

Lay on the side with the arm to be worked on the bottom. Start with the forearm parallel to the floor. Rotate the shoulder so that the forearm moves toward the stomach and hand points upward. Slowly lower the weight back to the start.

\section{Stretching}

Subjects were asked to perform two stretches for 30 seconds five sessions each day.

\section{The pectoralis minor stretch}

The subjects were asked to place each hand at shoulder height on adjacent walls of a corner and lean into the wall until a stretch was achieved.

\section{Anterior shoulder stretch}

Grasp something above you such as a door frame (or something similar if not tall enough). Move forward leaving the arm behind to stretch the front of the shoulder and chest muscles. Hold the position for 10 seconds.

\section{Posterior shoulder stretch}

Place one arm across the front and pull it in tight with the other. The subject should feel a gentle stretch at the back of the shoulder. Again, hold the position for 10 to 15 seconds and repeat 5 times. Ergonomical modification was given to both groups experimental as well as control group.

\section{Minimize awkward postures}

Standing on a stool, ladder, scaffolding or platform can minimize this reach and bring the work into a safer position.

\section{Handling tools}

Avoid handles that end in the palm as they create local contact stress. Add padding or sleeves to lengthen and soften such handles. Power tools create less torque than air tools, reducing forces. Many construction tasks, from turning a screwdriver to using equipment controls, require repetition. Make it a habit to stop their regular activity for a few minutes every hour. Post-test measurement had been taken after 6 weeks.

\section{RESULTS}

Table 1 shows that there is a significant reduction VAS and SPADI in Group A p $<0.05$ (Graph 1).

Table 2 shows that there is a significant reduction VAS and SPADI in Group B ( $<<0.05)$ (Graph 2).

Table 3 shows that there is a significant reduction VAS and SPADI in Group A compared to Group B ( $\mathrm{p}<0.05)$ (Graph 3).

\section{DISCUSSION}

The study objective was to determine the effects of home exercise program on shoulder pain and functional status in male construction workers. From Graphs 1-3, this study showed that significant reduction

Table 1: Comparison of pre- and post-mean values of VAS and SPADI of Group A

\begin{tabular}{lllll}
\hline Variables & $\mathbf{n}$ & Mean \pm SD & Significant & Z \\
\cline { 2 - 4 } & & Pre & Post & -3.578 \\
VAS & 15 & $5.87 \pm 0.352$ & $1.60 \pm 0.507$ & 0.000 \\
SPADI & 15 & $47.2893 \pm 3.95766$ & $10.5073 \pm 2.90073$ & -3.410 \\
\hline
\end{tabular}

VAS: Visual analog scale, SPADI: Shoulder pain and disability index, SD: Standard deviation

Table 2: Comparison of pre- and post-mean values of VAS and SPADI of Group B

\begin{tabular}{lllll}
\hline Variables & $\mathbf{n}$ & Mean \pm SD & \multirow{2}{*}{ Significant } \\
\cline { 3 - 5 } & & Pre & Post & \\
\hline VAS & 15 & $5.80 \pm 0.414$ & $2.80 \pm 0.414$ & -3.689 \\
SPADI & 15 & $43.1240 \pm 7.59179$ & $16.8681 \pm 2.51144$ & 0.000 \\
\hline
\end{tabular}

VAS: Visual analog scale, SPADI: Shoulder pain and disability index, SD: Standard deviation 
in pain and improvement in the functional status of construction workers in Group A than Group B.

Although exercise programs are commonly used as a conservative treatment for shoulder tendinitis and impingement syndromes, few randomized controlled studies have assessed the effects of shoulder exercise on symptoms or functional status.

Not many studies have targeted populations with an occupationally related shoulder impingement but in this study, physical therapy exercises (free exercises, shoulder stretching, and strengthening exercises) and ergonomic advices were compared.

The scapula provides a stable base for glenohumeral function and upper extremity function. There is a loss of glenohumeral mobility in a patient with the upper extremity symptoms, as this may affect scapular kinematics and adequate flexibility of the posterior capsule has been recommended before the initiation of a shoulder strengthening program [7].

This study revealed that there was a reduction in pain and improvement in functional status in experimental Group A $p<0.05$. This study is lined with Bang et al. reported significant improvements in subjects with shoulder impingement in shoulder function by physical therapy exercise treatment, shoulder stretching and strengthening exercises over a 1 month intervention period [8].

Similarly, the post-test values of VAS and SPADI shows significant improvement when compared to pretest values of control group $\mathrm{p}<0.05$ because some participants of control group reported that maintaining the good posture is difficult during the work time. This study was lined with James et al. reported that there is an average reduction in pain and pain-related disability in workplace ergonomic intervention $[5,9]$.

During this study I encountered some difficulty to explain about the study and the exercises. Some participants of this study reported that doing exercise after the work was difficult and feeling tired and bored in the experimental group.

This study shows there was a significant improvement in post-test values of the experimental group when compared to control group. This study was lined with, Grooten W J (2007) for subjects still at work, ergonomic intervention alone seemed to be ineffective for reducing neck/shoulder and the low back pain and pain-related disability.

This study revealed that physical therapy exercise protocol in the early stage is better when compared to ergonomic corrections. Hence, this study concluded that home-based exercises were important in treatment for shoulder impingement syndrome.

R. Lancelohanse (1995) et al. concluded that a modification of standard shoulder stretching techniques involving internal rotation. It is believed that this modification improves the effectiveness of the least efficient component of the shoulder stretching regimen.

Werner et al. concluded that strengthening of the centering muscles around the humeral head leads to good results in the nonoperative treatment of subacromial impingement [10].

Table 3: Comparison of post mean values of VAS and SPADI between Group A and Group B

\begin{tabular}{llllll}
\hline Variables & $\begin{array}{l}\text { Group A } \\
\text { mean }\end{array}$ & $\begin{array}{l}\text { Group B } \\
\text { mean }\end{array}$ & Post Mean \pm SD & Z value & Significant \\
& 1.60 & 2.80 & $2.20 \pm 0.761$ & -4.415 & 0.000 \\
VAS & 10.507 & 16.868 & $13.688 \pm 4.1919$ & -4.125 & 0.00 \\
SPADI & &
\end{tabular}

VAS: Visual analog scale, SPADI: Shoulder pain and disability index, SD: Standard deviation
Musculoskeletal changes during free exercises: It will increases the joint range of motion and it prevents the further injuries, it reduces the impingement of supraspinatus tendon $[10,11]$.

Strengthening, the muscle that will help the shoulder joint stable. Keeping thesemuscles strong can relieveshoulder pain and preventfurtherinjuries. Darshna Bennadi et al., stated that most of the dentists were of the hazards and they took preventive measures in the form of stretching exercises and ergonomic modifications [12].

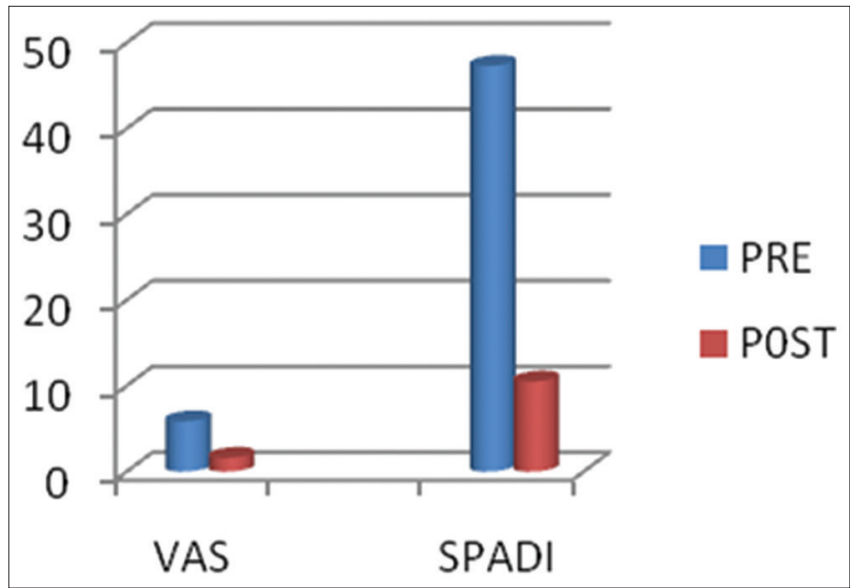

Graph 1: Comparison of pre- and post-mean values of visual analog scale and shoulder pain and disability index of Group A

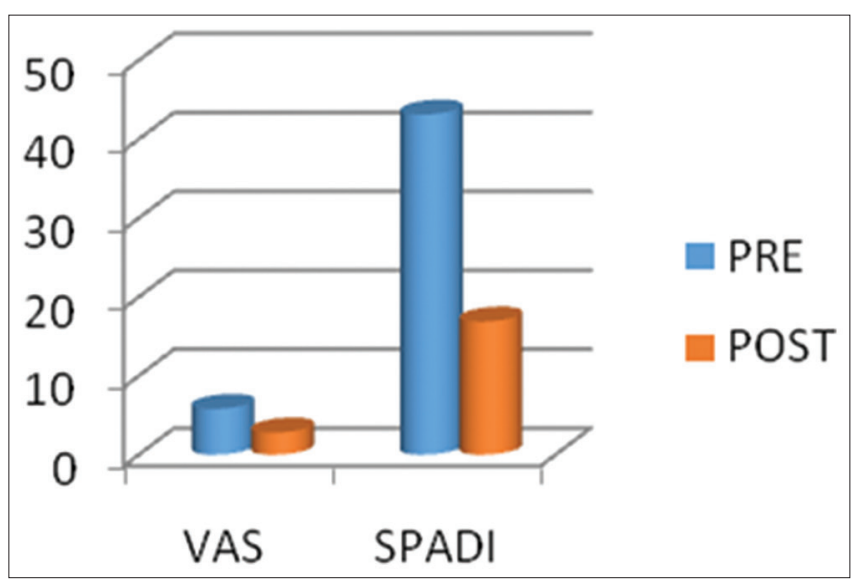

Graph 2: Comparison of pre- and post-mean values of visual analog scale and shoulder pain and disability index of Group B

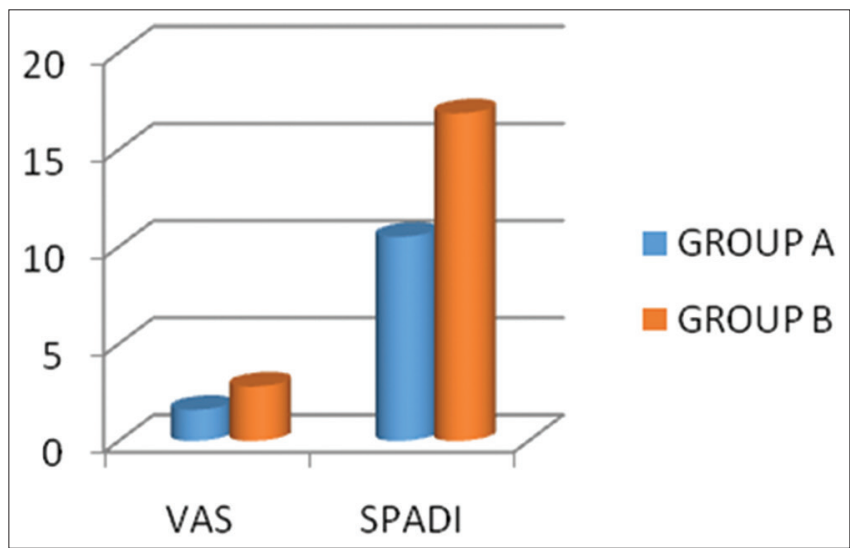

Graph 3: Comparison of post mean values of visual analog scale and shoulder pain and disability index between Group $A$ and Group B 
Stretching is important for restoring range of motion and preventing injury. Gentle stretching after strengthening exercises physiologically reduce muscle soreness, and keep the muscle long and flexible. Increased movement efficiency, decreased risk of injury, increased blood supply and nutrients to joint structures, increased neuromuscular coordination, reduced muscular tension, improved balance, and postural awareness $[13,14]$. Ayman S Soliman et al. concluded that both LASER and reflexology significantly reduced shoulder pain and increase the range of motion in Type II diabetic patients [15]. Arshpreetkalsi et al. concluded that regular stretching and physical exercises prevent various diseases and obesity [16].

On comparing the pre- and post-mean values of VAS and SPADI of Groups A and B, Group A was more significant than Group B.

There was strong evidence that shoulder strengthening exercise was an effective treatment for several conditions including shoulder impingement and shoulder disability.

\section{CONCLUSION}

The study concluded that there was a significant reduction in shoulder pain and improvement in shoulder functional status by home exercise program than ergonomic advices in male construction workers. Future studies have to be conducted with different age group. The study could be conducted with a longer duration home exercise program can be used for other degenerative conditions.

\section{REFERENCES}

1. Bjelle A, Hagberg M, Michaelson G. Occupational and individual factors in acute shoulder-neck disorders among industrial workers. Br J Ind Med 1981;38(4):356-63.

2. Hagberg $M$, Wegman DH. Prevalence rates and odds ratios of shoulder-neck diseases in different occupational groups. Br J Ind Med 1987;44(9):602-10.
3. Neer CS $2^{\text {nd }}$. Impingement lesions. Clin Orthop Relat Res 1983;70-7.

4. Fu FH, Harner CD, Klein AH. Shoulder impingement syndrome. A critical review. Clin Orthop Relat Res 1991;162-73.

5. Albers JT, Estill CF. Simple Solutions: Ergonomics for Construction Workers. Cincinnati, OH: National Institute for Occupational Safety and Health; 2007.

6. Kishner C, Colby LA. Therapeutic Exercises: Foundations and Techniques. $6^{\text {th }}$ ed. Philadelphia: F. A. Davis Company; 2002. p. 68-217.

7. Kamkar A, Irrgang JJ, Whitney SL. Nonoperative management of secondary shoulder impingement syndrome. J Orthop Sports Phys Ther 1993;17(5):212-24.

8. Bang MD, Deyle GD. Comparison of supervised exercise with and without manual physical therapy for patients with shoulder impingement syndrome. J Orthop Sports Phys Ther 2000;30(3):126-37.

9. Ludewig PM, Cook TM. Alterations in shoulder kinematics and associated muscle activity in people with symptoms of shoulder impingement. Phys Ther 2000;80(3):276-91.

10. Wang $\mathrm{CH}, \mathrm{McCl}$ re P, Pratt NE, Nobilini R. Stretching and strengthening exercises: their effect on three-dimensional scapular kinematics. Arch Phys Med Rehabil 1999;80(8):923-9.

11. Chakravarty K, Webley M. Shoulder joint movement and its relationship to disability in the elderly. J Rheumatol 1993;20(8):1359-61.

12. Bennadi D, Reddy V, Thummala NR. Preventive and curative measures adopted by dentists to combat occupational hazards. Int J Pharm Pharm Sci 2015;7(10):416-8.

13. Chard MD, Hazleman BL. Shoulder disorders in the elderly (A hospital study). Ann Rheum Dis 1987;46(9):684-7.

14. Williams JW Jr, Holleman DR Jr, Simel DL. Measuring shoulder function with the shoulder pain and disability index. J Rheumatol 1995;22(4):727-32.

15. Soliman AS, Mohmound AM, Serry Z, Dawood F. Therapeutic effects of low level laser therapy and reflexology on adhesive capsulitis in elderly Type II diabetic patients. Asian J Pharm Clin Res 2014;7(5):317-21.

16. Kalsi A, Singh S, Taneja N, Kukal S, Mani S. Current treatment for Type 2 diabetes, their side effects and possible complementary treatments. Int J Pharm Pharm Sci 2015;7(3):157-60. 